\title{
Production of renewable fuels by blending bio-oil with alcohols and upgrading under supercritical conditions
}

\author{
Sainab Omar ${ }^{1}$, Suzanne Alsamaq ${ }^{1}$, Yang Yang $^{2}$, Jiawei Wang $(\bowtie)^{1,2}$ \\ 1 Chemical Engineering and Applied Chemistry, Aston University, Birmingham, B4 7ET, UK \\ 2 European Bioenergy Research Institute, Aston University, Birmingham, B4 7ET, UK
}

(C) The Author(s) 2019. This article is published with open access at link.springer.com and journal.hep.com.cn 2019

\begin{abstract}
The work studied a non-catalytic upgrading of fast pyrolysis bio-oil by blending under supercritical conditions using methanol, ethanol and isopropanol as solvent and hydrogen donor. Characterisation of the bio-oil and the upgraded bio-oils was carried out including moisture content, elemental content, $\mathrm{pH}$, heating value, gas chromatography-mass spectrometry (GCMS), Fourier transform infrared radiation, ${ }^{13} \mathrm{C}$ nuclear magnetic resonance spectroscopy, and thermogravimetric analysis to evaluate the effects of blending and supercritical reactions. The GCMS analysis indicated that the supercritical methanol reaction removed the acids in the bio-oil consequently the $\mathrm{pH}$ increased from 2.39 in the crude bio-oil to 4.04 after the supercritical methanol reaction. The ester contents increased by $87.49 \%$ after the supercritical methanol reaction indicating ester formation could be the major deacidification mechanism for reducing the acidity of the bio-oil and improving its $\mathrm{pH}$ value. Simply blending crude bio-oil with isopropanol was effective in increasing the $\mathrm{C}$ and $\mathrm{H}$ content, reducing the $\mathrm{O}$ content and increasing the heating value to 27.55 from $17.51 \mathrm{MJ} \cdot \mathrm{kg}^{-1}$ in the crude bio-oil. After the supercritical isopropanol reaction, the heating value of the liquid product slightly further increased to $28.85 \mathrm{MJ} \cdot \mathrm{kg}^{-1}$.
\end{abstract}

Keywords bio-oil, blending, supercritical, upgrading, characterisation

\section{Introduction}

Due to global concerns such as depletion of fossil fuels, accelerated population growth, increase in energy demand, and crude oil price fluctuations, alternative energy sources such as biomass has received considerable attention.

Received November 27, 2018; accepted May 11, 2019

E-mail: j.wang23@aston.ac.uk
Biomass can be utilised as a renewable feed for conversion into gaseous, liquid, and solid bio-fuels [1]. Second generation feedstocks, which are mainly lignin and cellulose-based such as forest product residues, are a sustainable alternative to first generation feedstocks which pose food security concerns. Fast pyrolysis is a thermal conversion technique which decomposes biomass in the absence of oxygen [1]. Pyrolysis liquid (bio-oil) is produced under moderate temperature $\left(\sim 500^{\circ} \mathrm{C}\right)$ and short vapor residence times ( 1 s) [1]. Fast pyrolysis for liquid production is especially interesting as the process directly converts biomass to high yield liquid of up to 75 wt- $\%$ whilst keeping gas and char by-products at low yields of 12 and 13 wt-\% yields [2]. Common feedstocks for pyrolysis oil production include wood, bagasse, rice straw, switchgrass and wheat straw [3]. However, the properties of crude pyrolysis oil such as high acidity and viscosity and high oxygen and water contents lead to detrimental effects during application including corrosion to metal component, instability during storage and reduced heating value [1]. This affects the direct use of crude biooil and its assimilation into existing liquid fuel infrastructures.

Bio-oil upgrading by hydrotreatment has been widely researched and proven to effectively remove or reduce the oxygen content in the bio-oil to improve its quality and stability [4]. However, the severe process conditions $\left(350^{\circ} \mathrm{C}-450^{\circ} \mathrm{C}, 5-15 \mathrm{MPa}\right)$ leads to the formation of excessive amounts of gases and char as by-products [5]. Moreover, due to the high oxygen content (30-55 wt-\%) of bio-oil, a substantial amount of hydrogen is necessary for complete hydrogenation [6]. Thus, the direct hydrodeoxygenation of bio-oil is a high cost and low hydrogen efficiency process. This has motivated research into developing the hydrotreatment process to operate at lower temperature and without supply of hydrogen.

Recently, Gutiérrez Ortiz et al. proposed an integrated and energy self-sufficient municipal solid waste valorisa- 
tion process [7]. The system includes hydrogen production, by supercritical water reforming (SCWR) of bio-oil aqueous phase, and application of the produced hydrogen during hydrodeoxygenation of the organic bio-oil phase. SCWR can be used to convert wet biomass and organic wastes into $\mathrm{CO}_{2}, \mathrm{CO}, \mathrm{CH}_{4}$, and $\mathrm{H}_{2}$. The process does not require vaporising water for steam, which is typically carried out in steam reforming processes, thus SCWR has lower energy requirements. Moreover, this integrated system eliminates the need for external high-pressure hydrogen to upgrade the organic bio-oil phase by hydrodeoxygenation.

In conventional liquid phase catalytic hydrogenation reactions, hydrogen is mixed with a liquid substrate and a solid catalyst. Thus, gas-liquid transfer resistances and external fluid film diffusion resistances take place [8]. These mass transfer resistances can be removed by operating in supercritical conditions [9]. Hydrogen is insoluble in most organic solvents, but it is soluble in supercritical fluids. Thus, hydrogen concentration at the catalyst surface is increased under supercritical conditions resulting in higher reaction rates than in liquid phase reactions [8]. Bio-oil upgrading in supercritical fluids has been researched as an alternative to promote the bio-oil upgrading processes, since the challenges associated with catalytic bio-oil upgrading processes (i.e., expensive precious metal catalyst and external $\mathrm{H}_{2}$ addition, possibility of catalyst deactivation due to contaminants in crude bio-oil and coking on active sites) are not encountered with supercritical fluid upgrading [10-12]. Peng et al. compared bio-oil upgrading in ethanol under conventional $\left(100^{\circ} \mathrm{C}\right)$, sub-critical $\left(238^{\circ} \mathrm{C}\right)$ and supercritical $\left(260^{\circ} \mathrm{C}\right)$ conditions respectively and found operating under supercritical conditions was more effective for cracking the heavy components in the bio-oil compared to sub-critical conditions [13]. Jo et al. used supercritical alcohol for bio-oil upgrading without a catalyst and external hydrogen to improve the economics of the upgrading process [14]. The study showed supercritical methanol was very effective in upgrading as it produced high bio-oil yield, decreased the acidity of the bio-oil and increased the heating value.

Alcohols, such as methanol, ethanol, and isopropanol have been used to blend with bio-oil to increase its homogeneity and reduce its viscosity and the rate of ageing [15-25]. Diebold and Czernik found additives such as methanol and ethanol can drastically reduce the ageing rate of pyrolysis oil [25]. Methanol participated in molecular dilution to slow the chemical reactions and formation of intermediate products during storage. Boucher et al. also demonstrated the effective role of methanol solvent in reducing ageing and improving stability of bio-oil [15]. The addition of methanol to bio-oil hindered phase separation, lowered ageing rate and restricted polymerisation of the bio-oil components. Moreover, the viscosity of the methanol/oil blend was significantly lower than the untreated bio-oil. Likewise, Pidtasang et al. found the addition of methanol or ethanol significantly reduced the bio-oil viscosity (initial bio-oil viscosity 21 to $7 \mathrm{cSt}$ bio-oil/ alcohol blend) [18]. Yu et al. found blending methanol or ethanol with bio-oil proved to be a simple and costeffective method for reducing the viscosity and improving homogeneity and stability of the bio-oil [22]. Udomsap et al. prepared various bio-oil-solvent samples including two samples of $10 \mathrm{wt}-\%$ methanol, or ethanol in pure biooil [24]. The authors reported that the solvents could terminate the chain of oligomers, and break polymer chains to lower molecular weight compounds. For example, oligomeric esters in the bio-oil may undergo transesterification with methanol or ethanol to form lower molecular weight methyl or ethyl esters, respectively [24,25]. Oasmaa et al. tested the effects of adding up to $10 \mathrm{wt} \%$ methanol, ethanol and isopropanol on the quality of liquids from fast pyrolysis forestry residue and pine [17]. The authors reported that the addition of alcohols improved the homogeneity and heating value and reduced the viscosity of pyrolysis liquids. After the addition of alcohol, the solubility of poorly water-soluble compounds (e.g., lignin dimers) in the pyrolysis liquids was improved. The decrease in viscosity was reportedly due to the stabilising effect of the alcohols on the water-insoluble fraction. Weerachanchai et al. experimented with two alcohols (ethanol and $n$-butanol) as co-solvent to improve miscibility of bio-oil in diesel and produce a stable homogenous phase fuel [21]. A miscible bio-oil-diesel-alcohol fuel blend was obtained with 40 vol-\% bio-oil, 10 vol-\% diesel and 50 vol- $\%$ ethanol or butanol. The product fuel properties were improved (i.e., reduced viscosity, acidity, and carbon residue) relative to the bio-oil. Similarly, Nguyen and Honnery investigated combustion capabilities of $10 \%, 20 \%$ and $40 \%$ bio-oil in ethanol blends [16]. The burning rates for the product fuel blends were comparable to diesel fuel.

Many researchers have reported on bio-oil blending with alcohols, and bio-oil upgrading using supercritical fluids, respectively. However, to the best of the authors' knowledge, a detailed study of blending bio-oil with alcohols followed by treatment with supercritical alcohols has not been conducted. This paper outlines the effects of bio-oil blending with alcohols (methanol, ethanol and isopropanol) followed by the effects of non-catalytic supercritical treatment of bio-oil-alcohol blends.

\section{Materials and methods}

\subsection{Materials}

The bio-oil used for this research was derived from softwood and obtained from Biomass Technology Group in the Netherlands. Chemically pure grade methanol, ethanol and isopropanol were obtained from the company 
VWR chemicals. The samples were labelled BM1 (bio-oil methanol blend), BE1 (bio-oil ethanol blend), BI1 (bio-oil isopropanol blend), BM2 (bio-oil methanol reaction products), BE2 (bio-oil ethanol reaction products), and BI2 (bio-oil isopropanol reaction products).

\subsection{Bio-oil blending and upgrading reactions}

The bio-oil-alcohol blends were each prepared by weighing a $50 \mathrm{wt}-\%$ sample of bio-oil in a glass container, then adding $50 \mathrm{wt}-\%$ alcohol solvent. A $50 \mathrm{~mL}$ stainless steel autoclave with a maximum operating pressure of $210 \mathrm{bar}$ was used for the bio-oil-alcohol reactions. In a typical run, a magnetic stirrer, bio-oil and alcohol (1:1 weight ratio) was transferred into the autoclave. Then the autoclave was sealed and placed on an Asynt ADS-HP-NT magnetic hotplate stirrer and an Asynt ADS-TC-NT temperature sensor with controller was inserted. The autoclave was purged with $\mathrm{N}_{2}$ to remove dissolved oxygen in the liquid and the oxygen in the reactor. A 2-way ball valve on the autoclave was connected to the $\mathrm{N}_{2}$ line in the fume cupboard with a rubber tube. The hotplate and the temperature controllers were set to the maximum temperatures of $310^{\circ} \mathrm{C}$ and $450^{\circ} \mathrm{C}$, respectively. The bio-oil methanol reaction gradually increased in temperature and after 40 minutes of continuous heating the autoclave contents exceeded methanol's critical point $\left(240^{\circ} \mathrm{C}\right.$ and 79.54 bar). Likewise, the bio-oil ethanol and bio-oil isopropanol reactions gradually increased in temperature and after $30 \mathrm{~min}$ of continuous heating surpassed the ethanol $\left(24^{\circ} \mathrm{C}\right.$ and $\left.63 \mathrm{bar}\right)$ and isopropanol $\left(236^{\circ} \mathrm{C}\right.$ and 49 bar) critical points, respectively. Each reaction lasted $2 \mathrm{~h}$ and the stirring rate was set to $1500 \mathrm{r} / \mathrm{min}$. At the end of the reaction, the hot plate was switched off and the reactor was placed in a water bath to cool.

\subsection{Product analysis and characterisation}

The mass balance was calculated by the difference in the weight of the autoclave body before and after the reaction. The solid products readily settled at the bottom of the autoclave. The liquid product was collected with a pipette and transferred into a glass sample vial. The solid product in the autoclave with the magnetic stirrer was weighed and the total solid product was calculated by subtracting the weight of the autoclave and the magnetic stirrer. The liquid product was measured and the gas product was calculated. The yields of the liquid product, solid residue, and gaseous products were calculated using Eqs. (1-3). The product yields were calculated using the following equations:

$$
\text { Liquid yield }(\text { wt- } \%)=\frac{\text { Liquid product }(\mathrm{g})}{\text { Bio-oil }(\mathrm{g})+\operatorname{Solvent}(\mathrm{g})} \times 100 \% \text {, }
$$

$$
\text { Solidyield }(\text { wt- } \%)=\frac{\text { Solid product }(\mathrm{g})}{\operatorname{Bio-oil}(\mathrm{g})+\operatorname{Solvent}(\mathrm{g})} \times 100 \%,
$$

$$
\begin{aligned}
\operatorname{Gas} y i e l d(w t-\%) & =100 \%-[(\text { liquid yield })(w t-\%) \\
+ & \text { solidyield }(\text { wt- } \%)] .
\end{aligned}
$$

By measuring the water content, $\mathrm{pH}$ and heating value of the original bio-oil, the bio-oil blends and the liquid reaction products a comparison can be made to discuss the effects of blending and supercritical alcohol reactions on bio-oil. Additionally, characterisation techniques such as GCMS, ${ }^{13} \mathrm{C}$ nuclear magnetic resonance spectroscopy (NMR) and Fourier transform infrared radiation (FTIR) provide insight into the changes in chemical compounds in the bio-oil samples. The moisture content of the pyrolysis oil and the distillate products was determined using Karl Fischer titration. The titration was performed using a Mettler Toledo V20 Volumetric Karl Fischer Titrator Solvent: 34817 Fluka Hydranal $^{\mathrm{TM}}$ and Working Medium K Reagent: 34816 Fluka Hydranal ${ }^{\mathrm{TM}}$ - Composite $5 \mathrm{~K}$. The acidity of the samples was measured using a Hanna instruments $\mathrm{pH}$ tester. The higher heating value (HHV) was measured using an IKA C 1 static jacket oxygen bomb calorimeter.

The composition of the bio-oil and treated bio-oils was analysed using a Varian 450 gas chromatograph, and a Varian 220 mass spectrometer. A Column Elite-1701 was used to separate the components $(30 \mathrm{~m}, 0.25 \mathrm{~mm}$ internal diameter, $0.25 \mu \mathrm{m}$ film thickness, $14 \%$ cyanopropylphenyl $/ 86 \%$ dimethyl polysiloxane stationary phase). Before GCMS analysis, each sample was first mixed with high performance liquid chromatography grade acetone at a sample: acetone ratio 1:3. Then, this sample/acetone was filtered with a $0.2 \mu \mathrm{m}$ polytetrafluoroethylene filter using a syringe. For each analysis, $0.5 \mu \mathrm{L}$ of sample was injected into the $\mathrm{GC}$ column, and the injection port was $250^{\circ} \mathrm{C}$. Helium was used as the carrier gas, with a 1:20 split ratio (sample to helium). The GC oven was held at $45^{\circ} \mathrm{C}$ for $2.5 \mathrm{~min}$, then heated at $5^{\circ} \mathrm{C} \cdot \mathrm{min}^{-1}$ to $260^{\circ} \mathrm{C}$, and held at this temperature for $7.5 \mathrm{~min}$. The flame ionisation detector was kept at a temperature of $50^{\circ} \mathrm{C}$. The mass spectra were obtained for a range of 45-300 ( $\mathrm{m} / \mathrm{z})$. Peak assignments were performed on the mass spectra using the NIST05 MS library and from assignments found in the literature.

${ }^{13} \mathrm{C}$ NMR characterization of bio-oil was recorded in dimethyl sulfoxide DMSO-d6 (Cambridge Isotope Laboratories, DLM-10TB) solution (25\% wt/wt) in a $5 \mathrm{~mm} \mathrm{NMR}$ tube (Wilmad, 528 PP-7) using a Bruker Advance 300 $\mathrm{MHz}$ NMR spectrometer. The ${ }^{13} \mathrm{C}$ NMR spectrum was obtained by powergated decoupling pulse sequence (ZGPG), $90^{\circ}$ pulse angle, $3 \mathrm{~s}$ pulse delay time, and a total of 12288 scans at $25^{\circ} \mathrm{C}$. The spectra phase, baseline 
correction, and integration were conducted with Topspin software 3.5.

A Perkin Elmer Pyris 1 thermogravimetric analyser was used to carry out thermogravimetric analysis (TGA) of the crude and treated bio-oils. TGA was carried out over the range $25^{\circ} \mathrm{C}-750^{\circ} \mathrm{C}$ at a heating rate of $10^{\circ} \mathrm{C} \cdot \mathrm{min}^{-1}$ under a nitrogen flow rate of $2 \mathrm{~mL} \cdot \mathrm{min}^{-1}$.

Elemental analysis to determine the carbon, hydrogen, nitrogen, sulphur, oxygen (CHNSO) contents of the bio-oil and treated bio-oils was conducted using a Thermo Fisher Scientific Flash 2000 CHNS-O Organic Elemental Analyzer, where the oxygen content was calculated by difference. The $\mathrm{H}_{2} \mathrm{O}$ content from the Karl Fisher moisture content analysis was used to present the CHNS of the treated samples on a dry basis, i.e., water-free basis.

The functional groups of the bio-oil and the treated biooils were characterised using a Perkin Elmer Frontier FTIR spectrometer. A spectral range of 400 to $4000 \mathrm{~cm}^{-1}$ was used and 16 scans were applied to each sample. Prior to all analysis, a background scan was carried out under ambient atmosphere.

\section{Results and discussions}

\subsection{Product yields}

The total liquid and solid mass balance closure was $80.90 \%, 90.75 \%$ and $91.37 \%$ after bio-oil methanol, ethanol and isopropanol reactions, respectively (Table 1). All the liquid products were visibly less viscous than the crude bio-oil, and no significant change in colour was observed after reacting the bio-oil with the alcohols. Apart from the water contained in the crude bio-oil, water can also originate from esterification reactions, re-polymerization of oligomers, hydrodeoxygenation, and hydrocracking of the solvents during the upgrading process [26].

Compared to ethanol $\left(\mathrm{C}_{2} \mathrm{H}_{5} \mathrm{OH}\right)$ and isopropanol $\left(\mathrm{C}_{3} \mathrm{H}_{8} \mathrm{O}\right)$, the hydroxyl concentration is the highest with methanol $\left(\mathrm{CH}_{3} \mathrm{OH}\right)$ and its molecular structure enables higher activity [27]. The hydrocarbon contribution is the highest with isopropanol and the longer alkyl chain could dissolve higher molecular weight products, which leads to relatively lower solid products [27]. This functional group contribution change affects the reactivity of the solvents and leads to differences in the mass balance of each reaction. These findings also correspond with the CHNS results (Table 2) which showed methanol treated bio-oil had the highest oxygen content, lowest carbon and hydrogen content while isopropanol treated bio-oil had the lowest oxygen content, highest carbon and hydrogen content. Prajitno et al. also reported higher oil and lower coke yield after supercritical ethanol reaction compared to supercritical methanol [10].

Coke, commonly reported as an undesired by product in bio-oil hydrocracking and hydrotreatment processes, is generally derived from the re-polymerization and overdehydration of oligomers [26]. Table 1 shows methanol reacted bio-oil (BM2) generated the highest solid yield, this is reflected in the CHNS and TGA results and is further discussed in Section 3.2 Physicochemical properties of bio-oil and treated bio-oils. Shafaghat et al. also found relatively higher char/coke yield after reacting bio-oil with supercritical methanol compared to supercritical ethanol [28].

Gaseous products can be formed from various reactions during the bio-oil upgrading process namely; cracking, decarboxylation, decarbonylation, methanation, and hydrodenitrogenation [29]. Table 1 indicates the bio-oil methanol reaction generated lower total liquid and solid product yield compared to the ethanol and isopropanol. This indicates higher gas yield was obtained after the methanol reaction and more of the bio-oil-methanol was decomposed into gas products than bio-oil-ethanol or biooil-isopropanol. This suggests methanol had a higher tendency, than ethanol or isopropanol, to promote cracking of the higher-molecular-weight bio-oil fractions and gas formation reactions during the upgrading process. The increase in methanol activity may have led to higher mass losses due to the increased volatility of the product. In addition, self-decomposition of the alcohols in their supercritical state may contribute to some fractions of the gas products [14].

3.2 Physicochemical properties of bio-oil and treated biooils

Table 2 summarises the results from the water content, heating value, $\mathrm{pH}$ and $\mathrm{CHNS}$ analysis. The water content was reduced after blending the bio-oil with methanol,

Table 1 Mass balance (\% mass fraction with respect to the original feed amount) of the products of bio-oil reactions with methanol, ethanol and isopropanol, respectively $\left(270^{\circ} \mathrm{C}, 100 \mathrm{bar}, 2 \mathrm{~h}\right)$

\begin{tabular}{|c|c|c|c|c|c|}
\hline \multirow{2}{*}{ Solvent } & \multicolumn{3}{|c|}{ Liquid yield /wt- $\%$} & \multirow{2}{*}{ Total solid yield /wt- $\%$} & \multirow{2}{*}{ Total gas yield ${ }^{\text {a) }} /$ wt- $\%$} \\
\hline & Total liquid yield & Water-free liquid yield & Water yield ${ }^{\mathrm{b})}$ & & \\
\hline Methanol & 59.68 & 41.91 & 17.77 & 21.22 & 19.10 \\
\hline Ethanol & 82.84 & 63.48 & 19.36 & 7.91 & 9.25 \\
\hline Isopropanol & 86.23 & 69.96 & 16.27 & 5.14 & 8.63 \\
\hline
\end{tabular}

a) Gas yield was calculated by difference assuming no losses; b) Water yield was calculated using the water content measured in Table 2 . 
Table 2 Physicochemical properties of liquid products of bio-oil reactions with methanol, ethanol and isopropanol

\begin{tabular}{|c|c|c|c|c|c|c|c|}
\hline \multirow{2}{*}{ Properties } & \multicolumn{3}{|c|}{ Bio-oil alcohol blends ${ }^{\text {a) }}$} & \multicolumn{3}{|c|}{ Bio-oil alcohol reaction liquid products ${ }^{\mathrm{a}}$} & \multirow{2}{*}{ Bio-oil } \\
\hline & BM1 & BE1 & BI1 & BM2 & BE2 & $\mathrm{BI} 2$ & \\
\hline $\mathrm{H}_{2} \mathrm{O}$ wt- $\%$ & $13.42(0.9)^{\mathrm{b})}$ & $12.27(0.3)$ & $11.90(0.7)$ & $29.78(0.3)$ & $23.37(0.2)$ & $18.87(0.4)$ & $31.69(0.3)$ \\
\hline $\mathrm{pH}$ & 3.67 & 3.54 & 3.06 & 4.04 & 3.84 & 3.80 & 2.39 \\
\hline $\mathrm{C}$ wt-\% ${ }^{\mathrm{c})}$ & $48.13(0.5)$ & $55.16(0.0)$ & $58.28(0.0)$ & $46.05(1.3)$ & $58.76(0.3)$ & $61.91(0.3)$ & $49.26(0.4)$ \\
\hline $\mathrm{H} \mathrm{wt- \%}{ }^{\mathrm{c})}$ & $9.52(0.1)$ & $10.06(0.1)$ & $10.35(0.1)$ & $9.60(0.4)$ & $10.52(0.1)$ & $10.36(0.1)$ & $7.91(0.0)$ \\
\hline $\mathrm{N} \mathrm{wt- \%}{ }^{\mathrm{c})}$ & $0.20(0.0)$ & $0.18(0.0)$ & $0.17(0.0)$ & $0.71(0.0)$ & $0.18(0.0)$ & $0.19(0.0)$ & $0.20(0.0)$ \\
\hline O wt- $\%$ c), d) & $42.16(0.6)$ & $34.60(0.1)$ & $31.20(0.0)$ & $43.63(1.7)$ & $30.53(0.4)$ & $27.54(0.2)$ & $42.63(0.4)$ \\
\hline $\mathrm{HHV} \mathrm{MJ/kg}{ }^{\text {e) }}$ & $21.56(0.9)$ & $25.60(0.2)$ & $27.55(0.0)$ & $23.03(1.1)$ & $27.55(0.2)$ & $28.85(0.1)$ & $17.51(0.1)$ \\
\hline
\end{tabular}

a) BM1, BE1, BI1 refers to bio-oil-methanol, bio-oil-ethanol and bio-oil-isopropanol blends; BM2, BE2, BI2 refers to bio-oil-methanol, bio-oil-ethanol and bio-oilisopropanol reaction products; ${ }^{\text {b) }}$ Mean \pm standard deviation; ${ }^{c)} \mathrm{CHNO}$ water-free basis for the blends and reaction products; ${ }^{\text {d) }}$ Oxygen content calculated by difference; e) HHV dry basis for the blends and reaction products HHV dry basis = HHVwet/ $\left(1-\mathrm{H}_{2} \mathrm{O} / 100\right)$; $\mathrm{S}$ contents are zero in all samples.

ethanol, and isopropanol. This decrease in the water content of bio-oil after blending with an alcohol solvent was previously observed by $\mathrm{Yu}$ et al. [22]. Pidtasang et al. reported that the water reduction is due to the dilution effect of the anhydrous alcohols [18]. After the supercritical alcohol reactions, BM2 exhibited the highest water content. This is due to esterification reactions of methanol and acids in the bio-oil occurred and generated water as a product $[18,30,31]$. Another reason for the increased water content after the supercritical methanol reaction compared to the methanol blend may be linked to the high gas yield after the methanol reaction (Table 1). As methanol and volatile products are decomposed to gas, the resulting liquid product obtains an increased concentration of water. On the other hand, lower gas yield (compared to methanol) after the bio-oil-isopropanol reactions indicates isopropanol did not decompose to gas and the water content does not significantly increase. Reducing the moisture in the bio-oil is crucial as it can lead to increased ignition delay and decreased combustion rate in an engine [32]. On the other hand, water in bio-oil is beneficial as it reduces the viscosity [22].

After the methanol, ethanol and isopropanol reactions a modest increase in $\mathrm{pH}$ was observed (Table 2). This correlates with the GCMS results (Table 3) which showed a decrease in acidic compounds in the bio-oil after the reactions compared to the blends and the untreated bio-oil. The elemental analysis gives the weight percent of $\mathrm{C}, \mathrm{H}, \mathrm{N}$, and $\mathrm{S}$ in the sample. The oxygen content was calculated by difference. The CHNS results in Table 2 show the $\mathrm{C}$ content slightly decreased while the $\mathrm{O}$ content increased after the methanol reaction compared to the bio-oil methanol blend. This may be linked to the high solid and gas yield after the supercritical methanol reaction which led to $\mathrm{C}$ and $\mathrm{H}$ loss and subsequent increased proportion of O. Carbon may be lost as solid and gas due to polymerisation reactions and decarboxylation, decarbonylation, methanation reactions, respectively [29]. This indicates the supercritical reaction is more reactive with methanol solvent than ethanol or isopropanol. Similarly, the mass balance results (Table 1) showed the highest solid yield was obtained after bio-oil-methanol reactions, hence heavy components from polymerisation reactions were collected as solid residue leaving a liquid product with lighter volatile compounds [10].

The heating value of the crude bio-oil was $17.51 \mathrm{MJ} \cdot \mathrm{kg}^{-1}$. Increasing the heating value of the crude bio-oil is essential for improving its combustion efficiency in engines [32]. Table 2 shows minimal changes in the heating value after the reactions compared to the respective blends. Hence, in this work the reaction provides insufficient improvements for the heating value compared to blending. The heating values of the blends and the reaction products increased according to the heating value of the added solvent, i.e., methanol $<$ ethanol $<$ isopropanol. Isopropanol treated bio-oil had the highest heating value because isopropanol has higher heating value than methanol and ethanol. An increase in $\mathrm{C}$ and $\mathrm{H}$ and reduction in $\mathrm{O}$ leads to higher energy density [33]. This is confirmed in this study were isopropanol treated bio-oil exhibited the highest $\mathrm{C}$ and $\mathrm{H}$ and lowest $\mathrm{O}$ content as well as the highest heating value $\left(28.85 \mathrm{MJ} \cdot \mathrm{kg}^{-1}\right)$. The heating values after the reactions $\left(23.03 \mathrm{MJ} \cdot \mathrm{kg}^{-1} \mathrm{BM} 2 ; 27.55 \mathrm{MJ}\right.$ $\cdot \mathrm{kg}^{-1} \mathrm{BE} 2 ; 28.85 \mathrm{MJ} \cdot \mathrm{kg}^{-1} \mathrm{BI}$ ) are comparably low compared to crude oil $\left(45.54 \mathrm{MJ} \cdot \mathrm{kg}^{-1}\right)$ or conventional gasoline (46.54 MJ $\mathrm{kg}^{-1}$ ) [34]. Nevertheless, the improvements in the heating value compared to the crude bio-oil indicates solvents addition is a simple and effective means for improving bio-oil properties.

\subsection{Characterisation of bio-oil and treated bio-oils}

\subsubsection{GC-MS analysis}

GC-MS was used to identify and quantify many of the molecular compounds present in the crude bio-oil, and the treated bio-oils. In order to examine the product distribution in the different samples, the chemicals identified in the 
GCMS were classified into eight groups (acids, phenols, esters, ketones, alcohols/ethers, aldehydes, sugar derivatives, and hydrocarbons) based on their functional groups. Table 3 provides a summary of the relative amounts of compound classes in the crude bio-oil and the treated biooils. The total relative area $(\%)$ of each group was obtained by adding the area $(\%)$ of each compound in each category. The chromatographic peak area $(\%)$ of a compound is considered linear with its concentration. Therefore, the corresponding chromatographic peak area $(\%)$ of the compounds can be compared. For example, the peak area (\%) of acetic acid after each reaction can be compared to examine the effects of the supercritical alcohols. Additionally, the peak area $(\%)$ can be used to compare the change of the relative content of the compound among the detected compounds $[32,35]$.

Compounds detected in the crude bio-oil include acetic acid, 2-methoxy-4-methyl-phenol, 1-(4-hydroxy-3-methoxyphenyl)-ethanone, and 4-Hydroxy-2-methoxycinnamaldehyde. Phenolic compounds, which can be produced from the degradation of lignin [14], exhibited the highest total area (\%) $(37.0 \%)$ in the raw bio-oil with compounds such as 2-methoxy-4-methyl-phenol and 2-methoxy-4-(1propenyl)-phenol, contributing to the high area (\%). Although the percentage of peak area does not represent the actual content of the compound, it is a strong indication that the crude bio-oil contains a large amount of phenolic compounds. The presence of the phenolic compounds in the crude bio-oil and after the reactions is consistent with the results reported by other researchers $[10,14,36,37]$.

After reacting the bio-oil with the various solvents, the number of identified esters and the relative area $(\%)$ of esters significantly increased relative to the crude bio-oil and the blends. Compared to acids, esters are more favoured in the fuel composition due to their reduced corrosive effect on the engine surface [28]. Esters could be produced from the esterification reaction between acids in the bio-oil and the corresponding alcohols (methyl/ethyl/ isopropyl esters after bio-oil methanol/ethanol/isopropanol reactions, respectively). Further esters can form during reactions between the alcohol solvents and acids derived from the intermediate products from the conversion of oxygenated compounds during the process [27,37]. Udomsap et al. reported that solvents such as methanol and ethanol could terminate the chain of oligomers when added to crude bio-oil and break polymer chains to lower molecular weight compounds [24]. For example, the transesterification of polymeric esters with alcohol to form lower molecular weight methyl or ethyl esters. The GCMS results in this report confirms this phenomenon. The product distribution of esters changed after reacting the bio-oil with each alcohol solvent. For example, Propanoic acid methyl ester, Propanoic acid ethyl ester, and Propanoic acid 1-methylethyl ester was detected after reacting the bio-oil with methanol, ethanol and isopropanol, respectively. These findings indicate supercritical methanol, ethanol and isopropanol can promote ester formation during bio-oil reactions without catalyst addition.

A corresponding decrease in acids was observed after the reactions which resulted in higher $\mathrm{pH}$ compared to the bio-oil-alcohol blends (Table 2). Ester formation could be the major deacidification mechanism for reducing the acidity of the bio-oil and improving its $\mathrm{pH}$ value. The biooil-methanol reaction generated the lowest acid content, this agrees with the $\mathrm{pH}$ results which showed methanol treated bio-oil exhibited the highest $\mathrm{pH}$ (4.04) compared to ethanol (3.84) or isopropanol (3.80). One reason for the lower $\mathrm{pH}$ in BI2 may be the higher presence of acids in BI2 compared to BM2 and BE2. The acids in the bio-oil were eliminated after reacting with methanol and decreased by $15.88 \%$ and $17.44 \%$ with after ethanol and isopropanol reaction compared to their respective blends

Esterification reactions produce water as a by-product, one of the reasons for the increased water content after reacting the bio-oil with methanol may be the higher esterification activity when reacting the bio-oil with methanol [18,27,30,31]. Methanol treated bio-oil exhibited

Table 3 Distribution of chemical composition in bio-oil samples. Detailed composition including the compounds in each group is included as a supplementary material

\begin{tabular}{lccccccc}
\hline \multirow{2}{*}{ Compound } & \multicolumn{9}{c}{ Total relative content area /\% } \\
\cline { 2 - 7 } & Bio-oil & BM1 & BM2 & BE1 & BE2 & BI1 & BI2 \\
\hline Acids & 4.63 & 4.33 & - & 4.66 & 3.92 & 5.79 & 4.78 \\
Phenols & 37.03 & 27.85 & 32.73 & 28.49 & 28.76 & 31.12 & 38.04 \\
Esters & 3.74 & 3.41 & 29.89 & 2.76 & 27.68 & 3.66 & 22.35 \\
Ketones & 17.40 & 12.99 & 13.12 & 13.22 & 11.42 & 13.64 & 15.33 \\
Alcohols/ethers & 9.62 & 23.60 & 10.75 & 22.54 & 14.31 & 13.57 & 4.75 \\
Aldehydes & 8.57 & 6.01 & - & 7.23 & - & -7.12 & - \\
Sugar derivatives & 6.83 & 7.19 & - & 7.94 & - & -9.01 & - \\
Hydrocarbons & - & - & 0.30 & - & 13.19 & 13.89 & 16.10 \\
Others & 12.22 & 14.61 & 13.24 & & 14.73 \\
\hline
\end{tabular}


the highest water and ester content $(29.78$ wt- $\% ; 29.89$ area $(\%)$, respectively), followed by ethanol ( $23.37 \mathrm{wt}-\% ; 27.68$ area (\%), respectively) and isopropanol (18.87 wt-\%; 22.35 area (\%), respectively). These findings indicate that the non-catalytic and non-external hydrogen dependent supercritical alcohol process can stabilize the bio-oil by reducing the corrosive acidic components and increasing the desirable compounds such as esters $[10,14]$.

The relative area count of phenolic compounds increased after the reactions compared to the respective blends. Li et al. also found the phenols were difficult to reduce without co-feeding the upgrading reactions with $\mathrm{Pt} / \mathrm{C}$ and hydrogen [38]. The ${ }^{13} \mathrm{C}$ NMR results (Fig. 4) also show increased content of aromatic carbons after the biooil methanol, bio-oil-isopropanol reactions and most of the aromatics are phenol derivatives [39]. Aromatics and cyclic compounds are less likely to transform compared to light oxygenated compounds due to the stronger $\mathrm{C}-\mathrm{C}$ bonds involved [40]. Additionally, the increase in methoxy-phenolic compounds after the reactions compared to the blends may be due to the depolymerisation of the lignin fraction in the bio-oil $[40,41]$.

The unsaturated double bonds at the substituted groups of phenols such as 2-methoxy-4-(1-propenyl)-phenol in the crude bio-oil and blends, significantly decreased after the reactions and the phenols with saturated substituted groups such as, 2-methoxy-4-propyl-phenol increased. Similar findings were also reported by Tang et al. who explained the double bonds were reduced by hydrotreating the bio-oil [42]. Moreover, the ${ }^{13} \mathrm{C}$ NMR findings (Fig. 4 also indicate supercritical alcohol treatment facilitate in the saturation of $\mathrm{C}=\mathrm{O}$ bonds. A decrease in carbonyl carbon content was observed after the supercritical alcohol reaction compared to the bio-oil-alcohol blends. This suggests the alcohols functioned as hydrogen donors and facilitated in situ hydrogenation of the unsaturated bonds. Another reason for the increase in the proportion of 2-methoxy-4-propyl-phenol after the reactions could be the due to conversion of 4-hydroxy-2-methoxycinnamaldehyde, which was not detected after the reactions [41].

Phenols and aldehydes in bio-oil can lead to thermal instability and can form carbonaceous deposits hence their removal or conversion into more stable compounds is favourable $[13,38]$. Aldehydes such as 5-hydroxymethyl2-furancarboxaldehyde (HMF) which are prevalent in the crude bio-oil and the blends are not detected after the reactions. 2,5-dimethylfuran (DMF) was detected in BM2, BE2, and BI2 although it was not present in the crude biooil and blends. Several researchers have examined the production of DMF by hydrogenolysis of biomass derived HMF [43-45]. DMF has received significant attention as a potential renewable liquid transportation fuel due to its favourable physical properties including high energy density $\left(30 \mathrm{MJ} \cdot \mathrm{kg}^{-1}\right)$, high research octane number $(\mathrm{RON}=119)$, and low volatility (boiling point range $92^{\circ} \mathrm{C}-94^{\circ} \mathrm{C}$ ) [44]. These values correspond to that of gasoline $\left(34 \mathrm{MJ} \cdot \mathrm{kg}^{-1}, \mathrm{RON}=89-96\right.$ and $96.3^{\circ} \mathrm{C}$ boiling point) [44]. Additionally, unlike ethanol, the low solubility of DMF in water $\left(2.3 \mathrm{~g}^{\cdot} \mathrm{L}^{-1}\right)$ enables its use as a fuel blend [44]. Interestingly, after bio-oil-ethanol reactions, 2-ethyl5-methyl-furan is detected and after bio-oil-isopropanol reactions, 2-methyl-furan is detected. Supercritical methanol may also transform furfural to 1,2-butanediol by hydrogenation and hydrolysis. This indicates the different effects of the solvents on the bio-oil.

The ketones were relatively unchanged by the varying alcohols in the blends and the reaction products and remained between 11-13 area (\%) except after the isopropanol reaction. A slightly higher total relative area count of ketones was observed after the bio-oil-isopropanol reaction (15.33 area $(\%))$. The increase in ketones could be due to cracking and transformations from carbohydrates in the bio-oil [31]. This indicates compared to aldehydes, reducing or converting ketones was more difficult.

\subsubsection{FTIR analysis}

FTIR enables identification of the molecules present in a sample and was used to gain insight into the class of compounds present in the crude bio-oil and the treated biooils. Table 4 shows the chemical compounds that can be found in the crude bio-oil, blends, and treated bio-oil at various frequency ranges. Figures 1-3 show the FTIR spectra of the crude bio-oil, and the alcohol treated biooils. The IR absorption bands were assigned based on literature [46]. The relative differences between the band heights correlate with the relative differences in the concentrations of the corresponding functional groups between the samples [47].

The peaks between $3500-3200 \mathrm{~cm}^{-1}$ were ascribed to $\mathrm{O}-\mathrm{H}$ stretching vibrations of phenols, polymeric $\mathrm{O}-\mathrm{H}$ and water impurities. The $\mathrm{O}-\mathrm{H}$ stretching intensity was increased in BM2, BE2, and BI2, respectively compared to their corresponding blends (i.e., BM1, BE1, BI1). This correlates with the results from the water content analysis which showed an increase in water content after the reactions compared to the blends. Likewise, the GCMS results showed the ester content significantly increased after the reactions indicating esterification reactions occurred which evolve water as a by-product. Additionally, the total relative area (\%) of phenol compounds increased after the reactions compared to the blends, thus, further contributing to the increased intensity in the peaks between $3500-3200 \mathrm{~cm}^{-1}$.

The peaks between $3200-2800 \mathrm{~cm}^{-1}$ and $1470-1350$ $\mathrm{cm}^{-1}$ were caused by $\mathrm{C}-\mathrm{H}$ stretching in methyl groups and deformation in methylene groups, respectively. These absorption bands increased in intensity from BM2, BE2 to $\mathrm{BI}$, where the strongest absorbance in these ranges was observed after the bio-oil-isopropanol reactions. This is 
Table 4 Classes of compounds identified in the bio-oil and treated bio-oils using FTIR analysis

\begin{tabular}{|c|c|c|c|c|c|c|c|c|c|}
\hline \multirow{2}{*}{$\begin{array}{l}\text { Frequency range } \\
/ \mathrm{cm}^{-1}\end{array}$} & \multicolumn{7}{|c|}{ Frequency range $/ \mathrm{cm}^{-1}$} & \multirow{2}{*}{ Group } & \multirow{2}{*}{ Class of compound } \\
\hline & Bio-oil & BM1 & BM2 & BE1 & BE2 & BI1 & BI2 & & \\
\hline $3500-3200$ & 3367 & 3357 & 3346 & 3359 & 3360 & 3359 & 3360 & $\mathrm{O}-\mathrm{H}$ stretching & $\begin{array}{c}\text { Phenols, polymeric } \\
\text { O-H, } \\
\text { water impurities }\end{array}$ \\
\hline $3200-2800$ & $\begin{array}{l}2927, \\
2853\end{array}$ & $\begin{array}{l}2929 \\
2840\end{array}$ & $\begin{array}{l}2946, \\
2837\end{array}$ & $\begin{array}{l}2974, \\
2929\end{array}$ & $\begin{array}{l}2975, \\
2930\end{array}$ & $\begin{array}{l}2971 \\
2932\end{array}$ & $\begin{array}{l}2972 \\
2934\end{array}$ & $\mathrm{C}-\mathrm{H}$ stretching & Alkanes-methyl group \\
\hline $1750-1650$ & 1709 & 1710 & 1703 & 1710 & 1703 & 1711 & $\begin{array}{l}1707 \\
1651\end{array}$ & $\mathrm{C}=\mathrm{O}$ stretching & Ketones, aldehydes \\
\hline $1650-1590$ & 1648 & 1603 & 1610 & 1603 & 1603 & 1605 & & $\begin{array}{c}\mathrm{C}=\mathrm{C} \text { stretching } \mathrm{C} \\
\text { alkene }\end{array}$ & -C multiple bond stretching \\
\hline$\sim 1600-1450$ & 1515 & 1515 & 1515 & 1515 & 1515 & 1515 & 1515 & $\begin{array}{c}\mathrm{C}=\mathrm{C} \text { stretching } \\
\text { aromatic }\end{array}$ & \\
\hline $1470-1350$ & $\begin{array}{l}1450 \\
1363\end{array}$ & $\begin{array}{l}1449 \\
1361\end{array}$ & $\begin{array}{l}1449, \\
1377\end{array}$ & $\begin{array}{l}1448 \\
1378\end{array}$ & $\begin{array}{l}1452 \\
1378\end{array}$ & $\begin{array}{l}1465 \\
1380\end{array}$ & $\begin{array}{l}1466 \\
1380\end{array}$ & $\mathrm{C}-\mathrm{H}$ deformation & Alkanes-methylene group \\
\hline $1300-950$ & $\begin{array}{l}1268 \\
1033\end{array}$ & $\begin{array}{l}1268 \\
1193 \\
1031\end{array}$ & $\begin{array}{l}1268, \\
1219, \\
1114, \\
1018\end{array}$ & $\begin{array}{l}1270 \\
1043\end{array}$ & $\begin{array}{l}1271, \\
1086, \\
1044\end{array}$ & $\begin{array}{l}1276, \\
1160, \\
1126, \\
1100, \\
1051\end{array}$ & $\begin{array}{l}1288, \\
1161, \\
1127, \\
1106, \\
1034\end{array}$ & $\begin{array}{l}\mathrm{C}-\mathrm{O} \text { stretching } \\
\mathrm{O}-\mathrm{H} \text { bending }\end{array}$ & $\begin{array}{l}\text { Primary, secondary, } \\
\text { tertiary alcohols, phenols }\end{array}$ \\
\hline $975-525$ & $\begin{array}{l}861 \\
811\end{array}$ & $\begin{array}{l}889 \\
812\end{array}$ & & $\begin{array}{l}878 \\
811\end{array}$ & 878 & $\begin{array}{l}949 \\
815\end{array}$ & $\begin{array}{l}949 \\
816\end{array}$ & $\mathrm{C}-\mathrm{H}$ bending & $\begin{array}{l}\text { Mono-, polycyclic, } \\
\text { substituted aromatic rings }\end{array}$ \\
\hline
\end{tabular}

because isopropanol has two methyl groups, ethanol has a methyl and methylene group, and methanol has a methyl group. This aligns with the GCMS results which showed longer chain esters formed in BI2 such as acetic acid, (1methylethoxy)-, 1-methylethyl ester, compared to BE2 (acetic acid, ethoxy-, ethyl ester) and BM2 (acetic acid, methoxy-, methyl ester).

The carbonyl stretch $\mathrm{C}=\mathrm{O}$ appears as an intense band from $1750-1650 \mathrm{~cm}^{-1}$. The supercritical methanol, ethanol, and isopropanol treated bio-oils show a notably decreased absorbance in this wavenumber range compared to the corresponding blends and the original bio-oil. This indicates the supercritical alcohol conditions were effective in transforming carbonyl containing compounds such as carboxylic acids and aldehydes. This confirms the GCMS results which showed a complete removal of aldehydes after the reactions, as well as, elimination of carboxylic acids with methanol treatment and decrease of acids after ethanol and isopropanol treatments. Additionally, the ${ }^{13} \mathrm{C}$ NMR results (Fig. 4) showed after the supercritical treatment the carbonyl carbons were reduced.

The peak at $1515 \mathrm{~cm}^{-1}$ is attributed to $\mathrm{C}=\mathrm{C}$ aromatic stretching. This peak is prominent in the bio-oil and the blends and decreases after the reactions in BM2, BE2, and $\mathrm{BI}$. This agrees with the GCMS results which indicated to the decrease in unsaturated double bonds at the substituted groups of phenols such as 2-methoxy-4-(1-propenyl)phenol and increase in phenols with saturated substituted groups such as, 2-methoxy-4-propyl-phenol.

The frequency range $1300-950 \mathrm{~cm}^{-1}$ corresponds to
$\mathrm{O}-\mathrm{H}$ bending and $\mathrm{C}-\mathrm{O}$ stretching of primary, secondary, tertiary alcohols, and phenols, as well as $\mathrm{C}-\mathrm{O}$ stretching of ethers. Isopropanol treated bio-oil exhibits a cluster of sharp peaks in this region which is ascribed to the long ester chains and propylated compounds formed after the reaction.

The $975-525 \mathrm{~cm}^{-1}$ wavenumber range corresponds to $\mathrm{C}-\mathrm{H}$ bending from aromatic rings. The spectrums of the bio-oil ethanol blend, and the supercritical ethanol treated bio-oil exhibit a sharp peak at $878 \mathrm{~cm}^{-1}$ which comes from the ethanol in the sample. The spectrums of the isopropanol blended, and supercritical isopropanol treated bio-oil shows a sharp peak at $950 \mathrm{~cm}^{-1}$ and $817-815 \mathrm{~cm}^{-1}$, which originates from the isopropanol in the sample.

\subsection{3 ${ }^{13} \mathrm{C}$ NMR analysis}

${ }^{13} \mathrm{C}$ NMR identifies the specific carbon atoms in a molecule and enables analysis of the carbon distribution in the biooil and the bio-oil treated samples. To obtain a complete characterization of the bio-oil and the treated bio-oils, ${ }^{13} \mathrm{C}$ NMR analysis was carried out and summarised in Fig. 4. The integrated ${ }^{13} \mathrm{C}$ NMR spectra were separated into five chemical shift ranges and the regions were assigned according to literature [48]: 163-215 ppm (carbonyl carbons), $110-163 \mathrm{ppm}$ (aromatic and $\mathrm{C}=\mathrm{C}$ carbons), 84-110 ppm (carbohydrate-type carbons), 54-84 ppm (methoxy- or hydroxy-bound carbons), 1-54 ppm (primary, secondary, tertiary, and most quaternary alkyl carbons). 


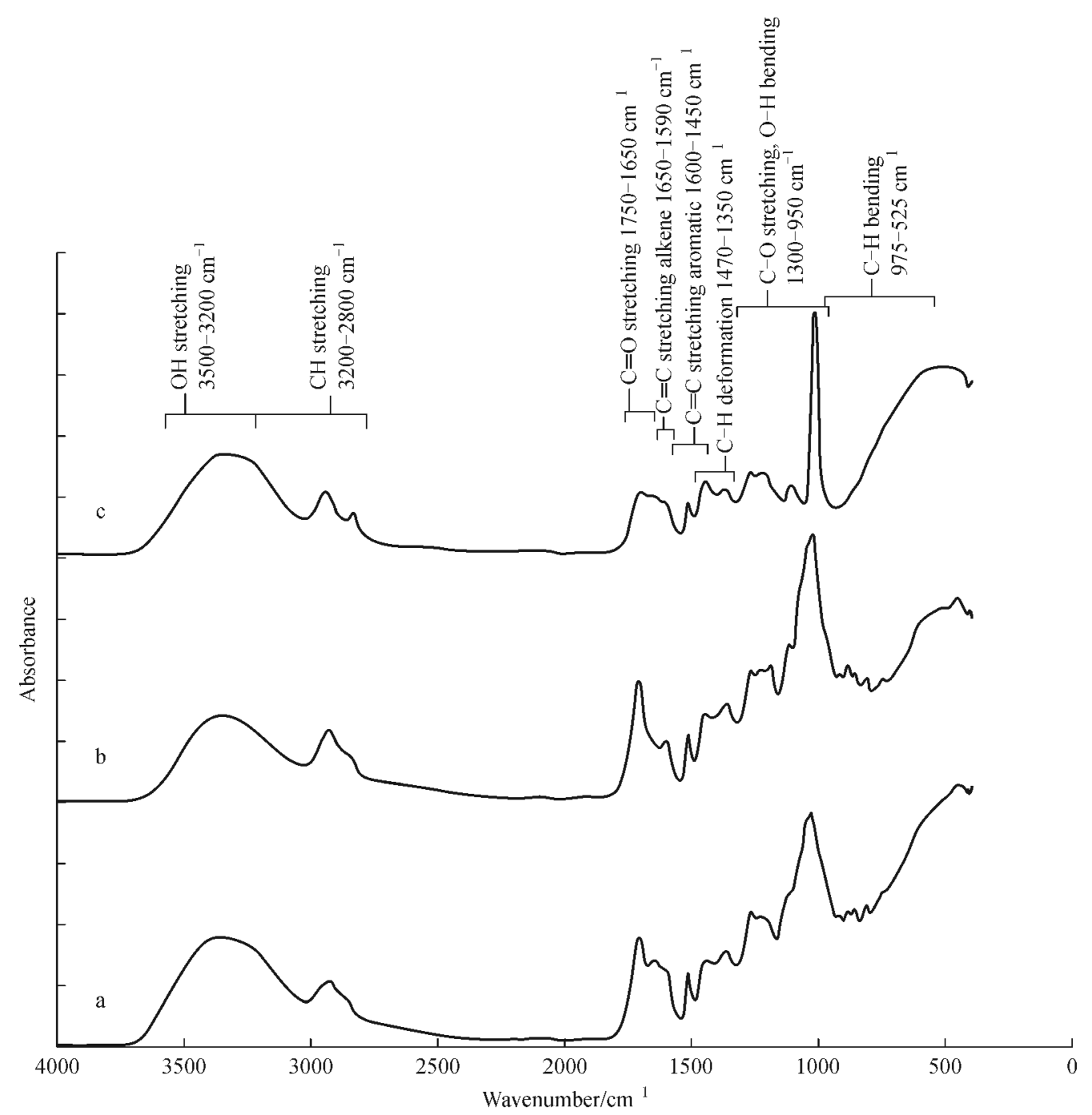

Fig. 1 FTIR spectra of (a) bio-oil, (b) bio-oil-methanol blend, and (c) bio-oil-methanol reaction products.

The alkyl carbons increased after the reactions relative to the crude bio-oil and the respective blends. This may be due to the dissociation of methyl, ethyl or isopropyl from methanol, ethanol and isopropanol, respectively as a result of the high temperature supercritical conditions. After the bio-oil methanol reaction, the methoxy/hydroxy carbons decreased, this is in line with the GCMS results were the alcohol and ether contents decreased in BM2 compared to BM1. According to ${ }^{13} \mathrm{C}$ NMR results the methoxy/hydroxy carbons did not significantly change after the bio-oil ethanol reaction, however, the GCMS results show alcohol and ether contents decreased in BE2. The latter is in line with the FTIR findings which showed after the bio-oilethanol reaction, the intensity of the peaks in 1300 $950 \mathrm{~cm}^{-1}$ frequency range (which corresponds to $\mathrm{O}-\mathrm{H}$ bending and $\mathrm{C}-\mathrm{O}$ stretching of primary, secondary, tertiary alcohols, as well as $\mathrm{C}-\mathrm{O}$ stretching of ethers) decreases compared to the bio-oil-ethanol blend and the crude bio- oil. The isopropanol treated bio-oil also demonstrated a decrease in methoxy/hydroxy carbons as well as alcohol and ether content in the ${ }^{13} \mathrm{C}$ NMR and GCMS results, respectively.

After the reactions, no resonances occurred in the carbohydrate carbon chemical shift ranges 84 to $110 \mathrm{ppm}$. Likewise, in the GCMS analysis, the sugar derivatives which were present in the crude bio-oil and blends were not detected after the reactions. This may be due to the depolymerisation of these compounds due to the supercritical conditions. Meng et al. reported that under high temperature conditions, the carbohydrates in bio-oil could decompose into various light-oxygenates [48]. Additionally, Li et al. indicated large amount of water from processed high boiling fraction of bio-oil may be linked to the dehydration of sugars [31].

The aromatic carbons in the bio-oils include carbons in phenolic compounds. The GCMS analysis demonstrated 


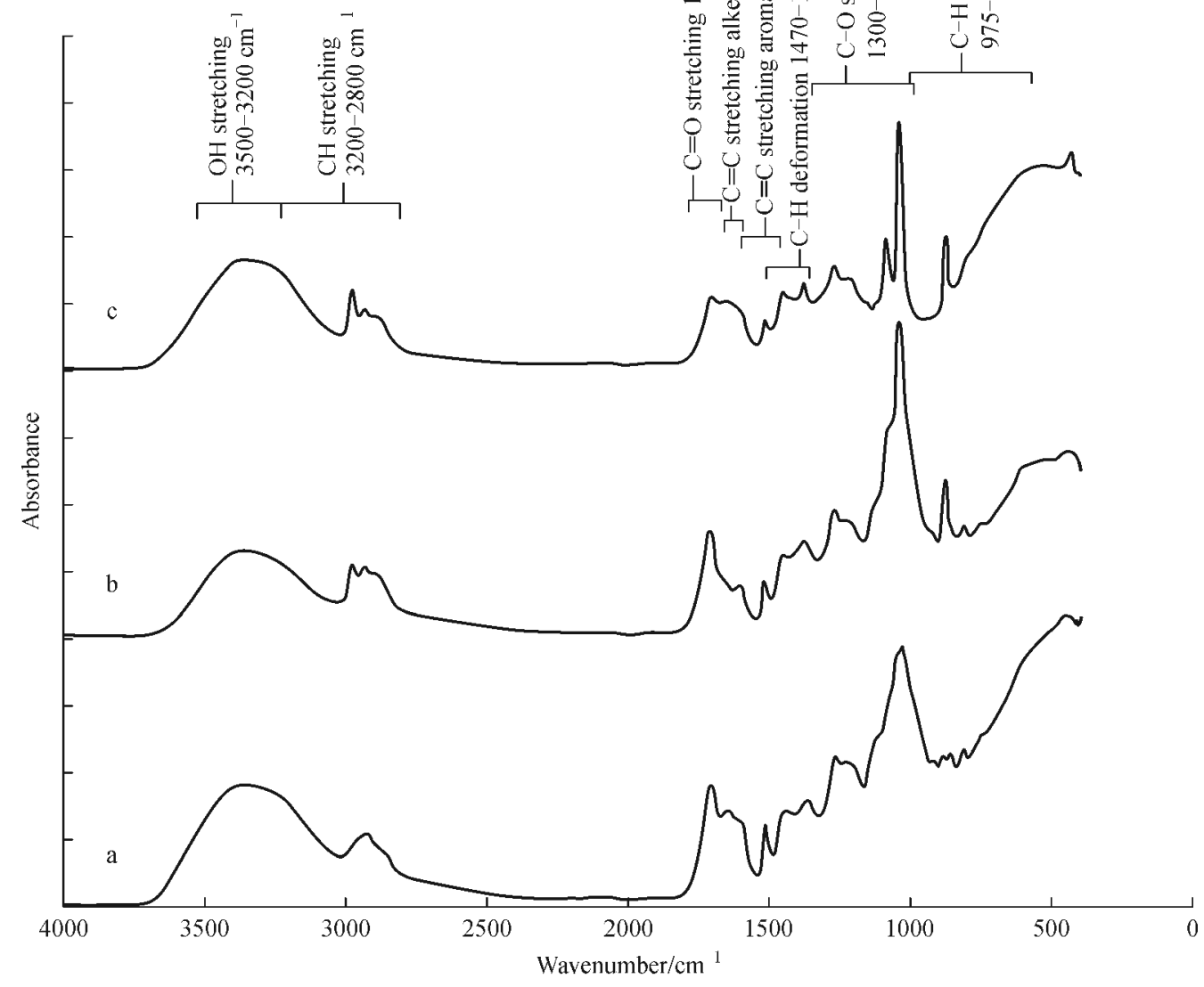

Fig. 2 FTIR spectra of (a) bio-oil, (b) bio-oil-ethanol blend, and (c) bio-oil-ethanol reaction products.

that phenolic compounds were less likely to transform during upgrading reactions compared to light oxygenated compounds due to the stronger $\mathrm{C}-\mathrm{C}$ bonds involved [40]. Likewise, the ${ }^{13} \mathrm{C}$ NMR findings show minimal changes occurred to the aromatic carbon content after the reactions. After the supercritical treatment the carbonyl carbons were reduced. This is consistent with the GCMS results of BM2, $\mathrm{BE} 2$, and BI2 which demonstrated transformations of acids and aldehydes. These findings also correspond to the FTIR results which showed supercritical alcohol treated bio-oil exhibited a decrease in carbonyl stretching compared to the crude bio-oil or bio-oil-alcohol blends.

\subsubsection{TGA analysis}

TGA analysis provides insight into the changes in the physical and chemical properties of a material as a function of increasing temperatures. The analysis results outlined the relative proportions of light and heavy fractions in biooil. Figures 5-7 compile the thermographic curves of the crude bio-oil and the methanol, ethanol and isopropanol treated bio-oils. The TG curve of the crude bio-oil shows the evaporation of moisture and highly volatile compounds in the bio-oil occurred between $27.69^{\circ} \mathrm{C}-337.36^{\circ} \mathrm{C}$ which resulted in $69.66 \%$ weight loss. The first decomposition of less volatile compounds in the bio-oil was observed between $384.01{ }^{\circ} \mathrm{C}-472.85^{\circ} \mathrm{C}$ and $5.63 \%$ of these compounds were removed. The final bio-oil decomposition region was between $521.98^{\circ} \mathrm{C}-696.60^{\circ} \mathrm{C}$ and $17.83 \%$ of heavy compounds were decomposed.

Figure 5 demonstrates the presence of the lighter methylated and methoxylated compounds in supercritical methanol treated bio-oil leads to the formation of a TG curve with faster weight loss rate than crude bio-oil and methanol blended bio-oil which contain relatively heavier compounds. In all three cases (methanol, ethanol and isopropanol) the weight loss rate of the supercritical 


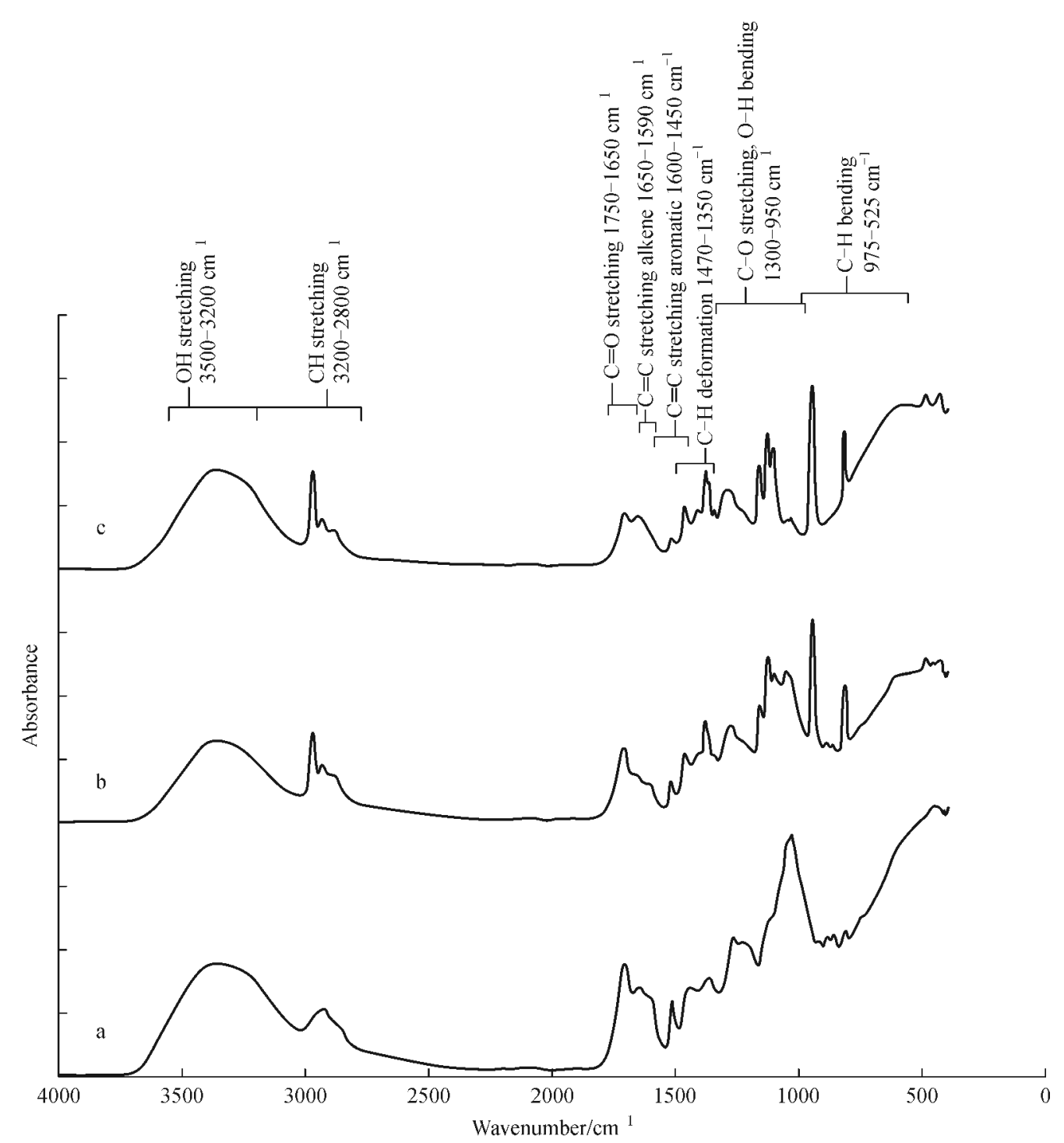

Fig. 3 FTIR spectra of (a) bio-oil, (b) bio-oil-isopropanol blend, and (c) bio-oil-isopropanol reaction products.

alcohol treated bio-oils are all faster than that of the original bio-oil. This is due to the volatilization of alcohol, water and other light components [42]. In supercritical methanol treated bio-oil a second peak can be observed at $\sim 100^{\circ} \mathrm{C}$ which is not apparent in the bio-oil-methanol blend. This may indicate to the formation of more water after the reaction which corresponds to the FTIR results which showed a higher absorbance in the $\mathrm{O}-\mathrm{H}$ wavenumber range after supercritical methanol treatment relative to the bio-oil-methanol blend.

The boiling point distribution of the bio-oil and treated bio-oils is illustrated in Table 5 and the distillation range was selected based on the reference [49]. Bio-oil treatment with supercritical methanol produced a liquid product with $62.79 \%$ of the material boiling between $35^{\circ} \mathrm{C}-150^{\circ} \mathrm{C}$, compared to $54.62 \%$ and $50.46 \%$ with supercritical ethanol and isopropanol, respectively. This agrees with the GCMS results which showed the greatest ester content after the bio-oil-methanol reactions. The methylated or methyoxylated compounds present in the bio-oil-methanol liquid products are more volatile than the ethanol and isopropanol counterparts. Additionally, the highest water content was observed after the bio-oil-methanol reactions; primarily due to water formed as a by-product of esterification reactions. These factors contribute to the increased volatile light compounds present after the supercritical methanol treatment. The material boiling between $35^{\circ} \mathrm{C}-150^{\circ} \mathrm{C}$ increased in BM2 and BE2 compared to their respective blends (i.e., BM1 and BE1) but decreased after supercritical isopropanol reaction 


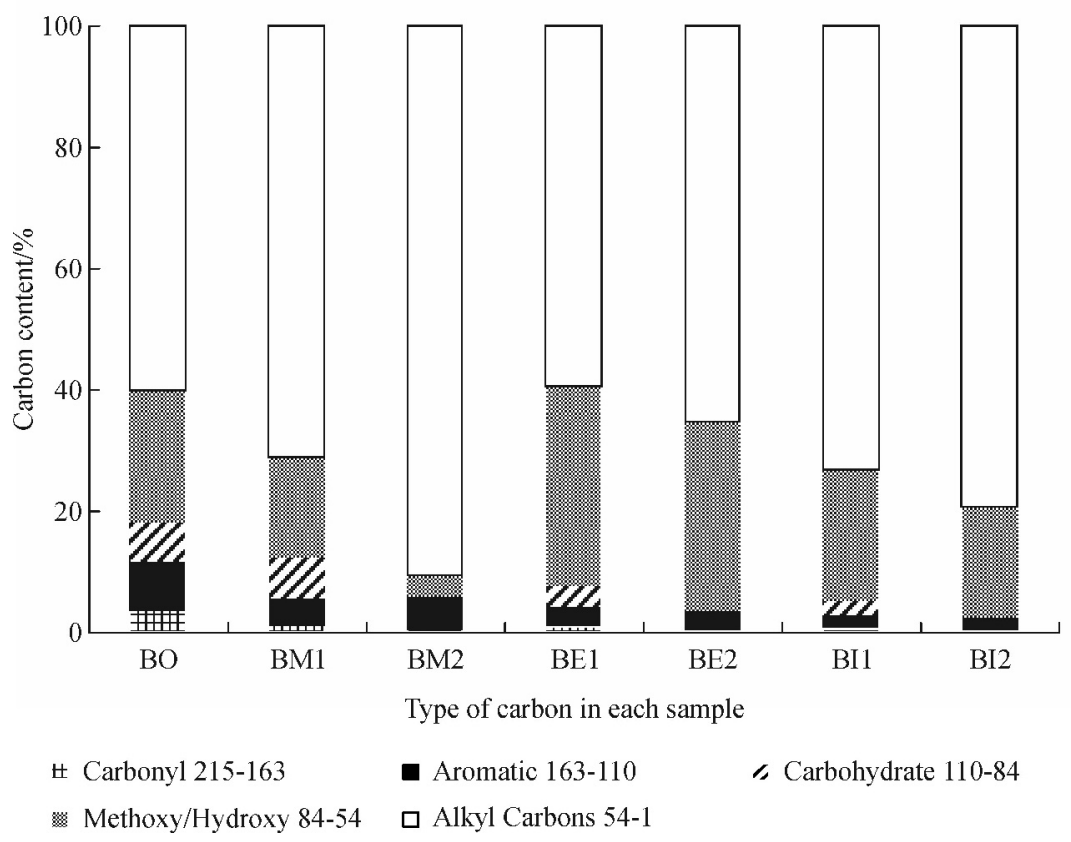

Fig. 4 Quantitative ${ }^{13} \mathrm{C}$ NMR characterisation of bio-oil and treated bio-oils. The integration range was selected based on ${ }^{13} \mathrm{C}$ NMR biooil characterisation by Meng et al. [48].

compared to the isopropanol blend. This may be due to the formation of higher boiling longer chain compounds after the isopropanol reaction.

\section{Conclusions}

The physical and chemical characteristics and the effects of blending crude bio-oil with methanol, ethanol, and isopropanol were investigated and compared to those of bio-oil treated with supercritical methanol, ethanol, and isopropanol. Additionally, the in situ hydrogenation method was examined for treating the crude bio-oil, rather than using external hydrogen addition. Bio-oil-supercritical methanol treatment tended towards high solid and gas yields which may be due to its higher reactivity compared to ethanol or isopropanol as indicated by the GCMS findings. GCMS analysis demonstrated that only supercritical methanol treatment eliminated the acids in the bio-oil, consequently, the $\mathrm{pH}$ increased from 2.39 in the crude bio-oil to 4.04 after the methanol reaction. This was attributed to the high esterification ability of supercritical methanol based on the significant amount of newly formed esters and the high water by-products from esterification reactions. Due to the high hydrocarbon contribution of isopropanol, after blending, the $\mathrm{C}$ and $\mathrm{H}$ content increased,

Table 5 Boiling point distribution of bio-oil and treated bio-oils distillation range $\mathrm{e}^{\text {a) }}$

\begin{tabular}{|c|c|c|c|c|c|c|c|}
\hline \multirow{2}{*}{$\begin{array}{l}\text { Distillation range } \\
{ }^{\circ} \mathrm{C}\end{array}$} & \multicolumn{7}{|c|}{ Weight $1 \%$} \\
\hline & $\mathrm{BO}$ & BM1 & BM2 & BE1 & BE2 & BI1 & BI2 \\
\hline $35-150$ & $41.31(0.5)^{\mathrm{b})}$ & $50.17(0.0)$ & $62.79(0.4)$ & $52.80(0.1)$ & $54.62(0.7)$ & $52.50(0.2)$ & $50.46(0.2)$ \\
\hline $150-200$ & $11.79(0.1)$ & $10.17(0.0)$ & $7.83(0.0)$ & $9.77(0.0)$ & $8.38(0.2)$ & $9.62(0.2)$ & $9.14(0.1)$ \\
\hline $200-250$ & $9.66(0.1)$ & $8.33(0.0)$ & $6.32(0.0)$ & $7.91(0.0)$ & $7.22(0.2)$ & $7.73(0.2)$ & $7.86(0.1)$ \\
\hline $250-300$ & $7.64(0.1)$ & $6.66(0.0)$ & $5.03(0.0)$ & $6.20(0.1)$ & $6.09(0.2)$ & $6.14(0.1)$ & $6.72(0.1)$ \\
\hline $300-350$ & $6.29(0.1)$ & $5.66(0.0)$ & $4.38(0.0)$ & $5.28(0.0)$ & $5.35(0.1)$ & $5.24(0.1)$ & $5.99(0.1)$ \\
\hline$<350$ & $76.70(0.9)$ & $80.99(0.0)$ & $86.36(0.4)$ & $81.97(0.0)$ & $81.66(0.0)$ & $81.24(0.3)$ & $80.18(0.2)$ \\
\hline $350-400$ & $5.50(0.0)$ & $5.00(0.0)$ & $4.07(0.0)$ & $4.70(0.0)$ & $4.94(0.2)$ & $4.64(0.1)$ & $5.53(0.1)$ \\
\hline $400-450$ & $4.72(0.1)$ & $4.42(0.1)$ & $3.63(0.0)$ & $4.20(0.0)$ & $4.38(0.1)$ & $4.13(0.1)$ & $4.83(0.0)$ \\
\hline $450-500$ & $4.20(0.1)$ & $3.93(0.1)$ & $3.17(0.0)$ & $3.74(0.0)$ & $3.90(0.0)$ & $3.67(0.1)$ & $4.20(0.0)$ \\
\hline$>500$ & $8.88(1.1)$ & $5.66(0.2)$ & $2.77(0.4)$ & $5.39(0.0)$ & $5.13(0.3)$ & $6.32(0.6)$ & $5.25(0.3)$ \\
\hline
\end{tabular}

a) The distillation range was selected based on [49]; b) Mean \pm standard deviation. 


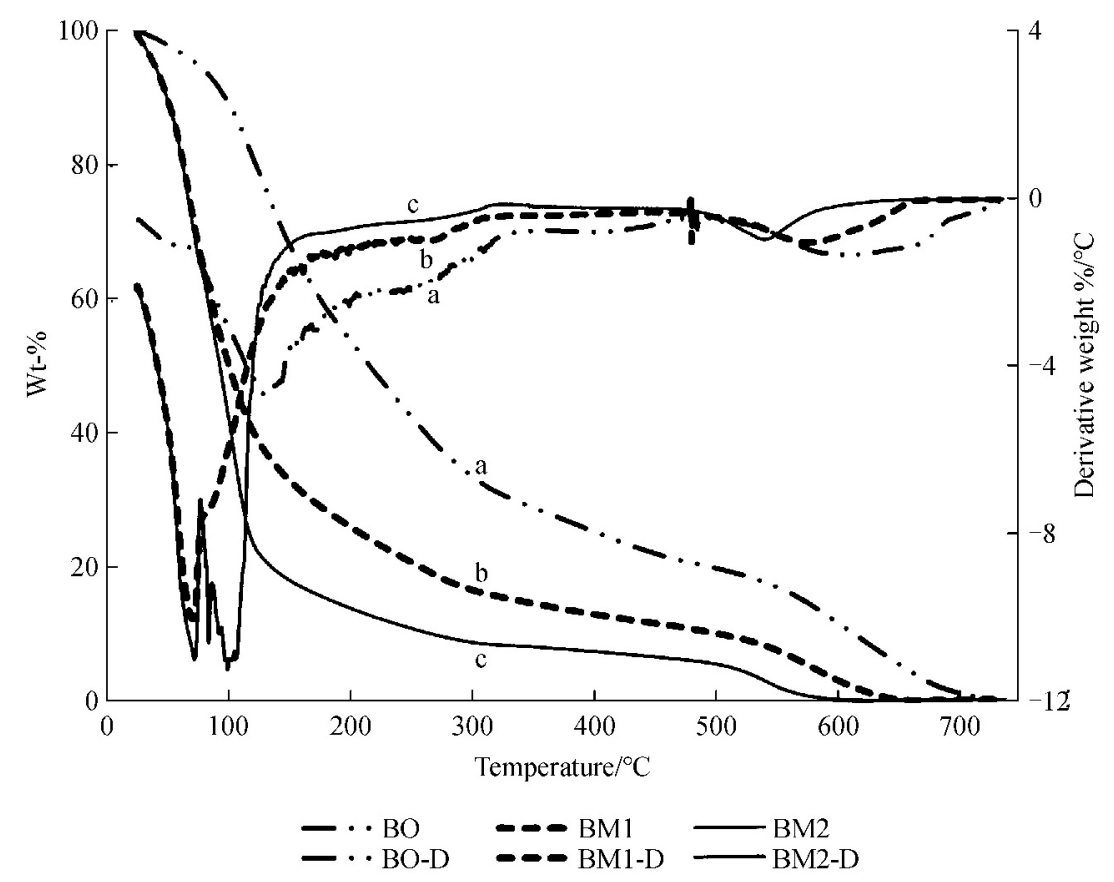

Fig. 5 TGA and DTG profiles of (a) bio-oil, (b) bio-oil-methanol blend, and (c) bio-oil-methanol reaction products.

and the $\mathrm{O}$ content was reduced compared to the crude biooil. As a result, the heating value improved from $17.51 \mathrm{MJ} \cdot \mathrm{kg}^{-1}$ in the crude bio-oil to $27.55 \mathrm{MJ} \cdot \mathrm{kg}^{-1}$ in the bio-oil-isopropanol blend. After the supercritical isopropanol reaction, the heating value of the liquid product further increased to $28.85 \mathrm{MJ} \cdot \mathrm{kg}^{-1}$. The improvements in the heating value compared to the crude bio-oil indicates solvents addition is a simple and effective method for improving bio-oil properties. In situ hydrogenation proceeded in all the reactions which was confirmed by the GCMS results which showed the transformation of aldehydes such as HMF to DMF. ${ }^{13} \mathrm{C}$ NMR and FTIR

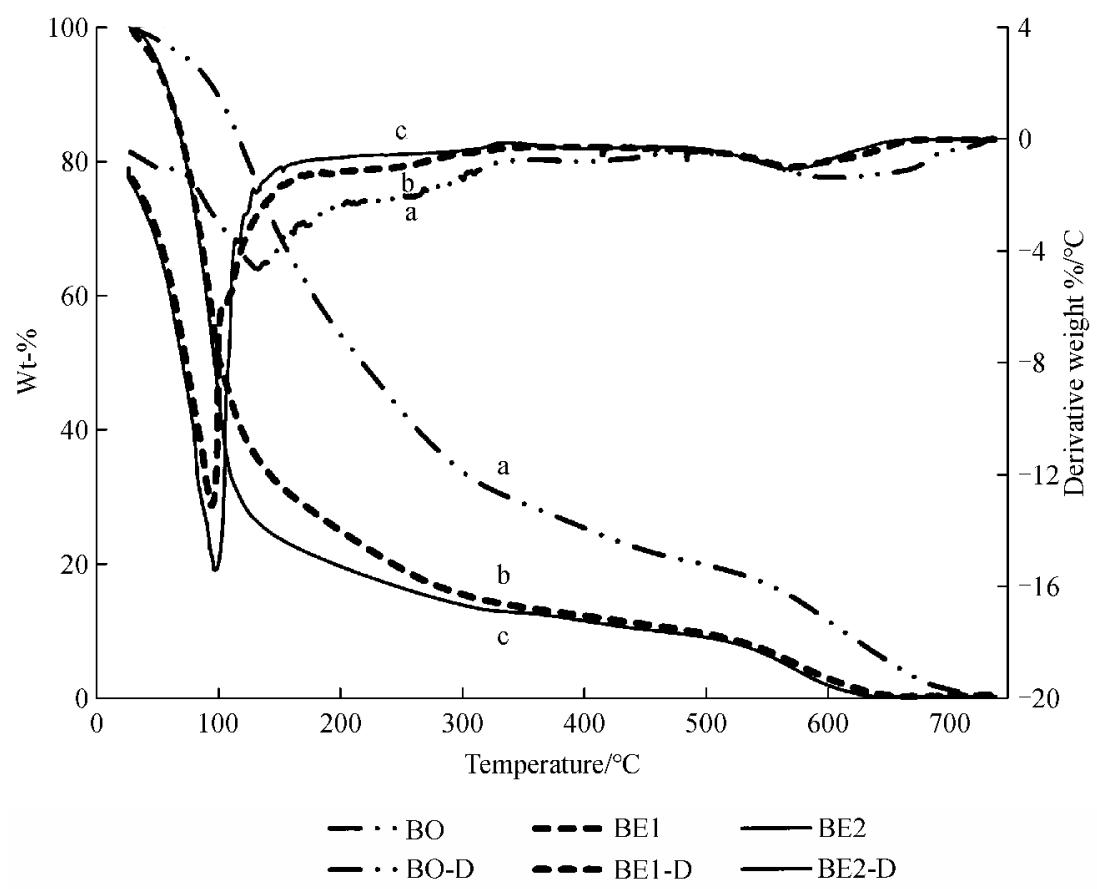

Fig. 6 TGA and DTG profiles of (a) bio-oil, (b) bio-oil-ethanol blend, and (c) bio-oil-ethanol reaction products. 


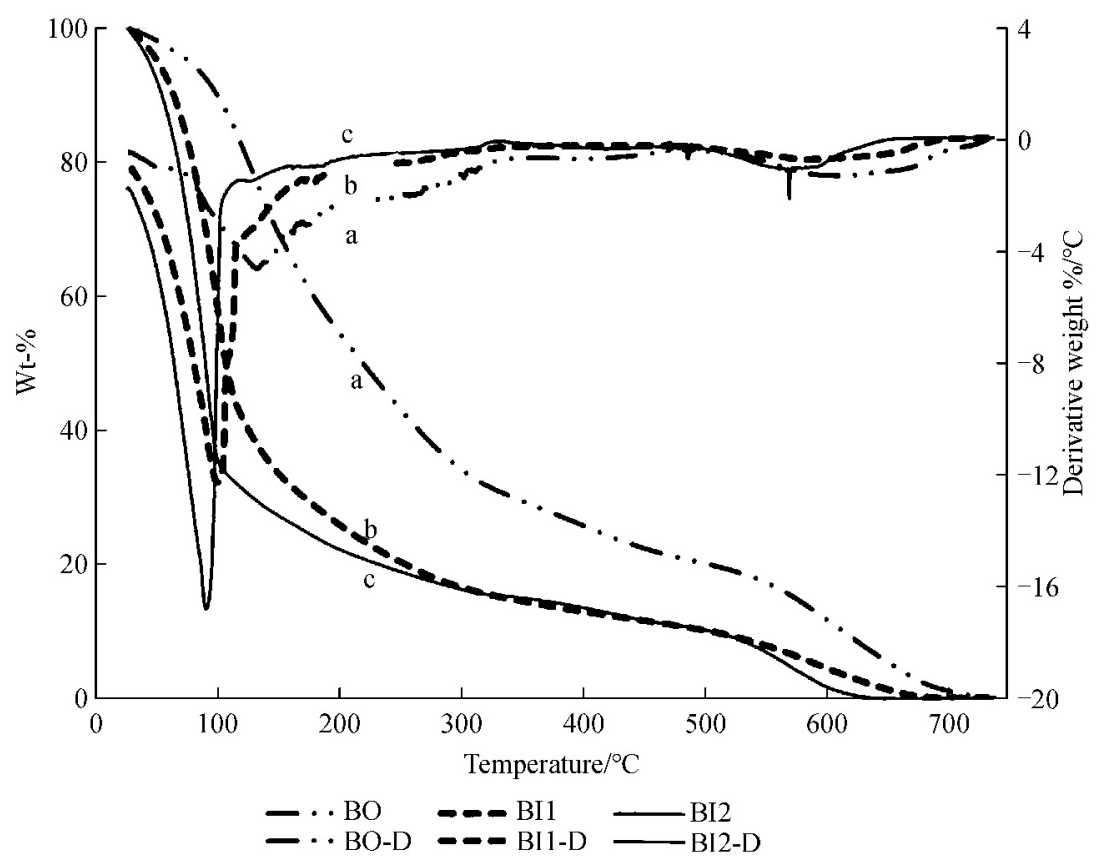

Fig. 7 TGA and DTG profiles of (a) bio-oil, (b) bio-oil-isopropanol blend, and (c) bio-oil-isopropanol reaction products.

results also indicated that in situ hydrogenation occurred due to the reduction in carbonyl compounds after the supercritical reactions and an increase in alkyl carbons in the ${ }^{13} \mathrm{C}$ NMR results. Although the bio-oil-alcohol blends improved certain bio-oil properties, (e.g., heating value and $\mathrm{pH}$ ), the supercritical reactions further enhanced the bio-oil properties by promoting reactions such as esterification and hydrogenation thus further improving the physicochemical properties of the bio-oil. For future work, efficient solvent recovery and reuse is necessary to optimise the process.

Acknowledgements The authors acknowledge the financial support received from Aston University, the School of Engineering and Applied Science, Chemical Engineering and Applied Chemistry department.

Open Access This article is licensed under a Creative Commons Attribution 4.0 International License, which permits use, sharing, adaptation, distribution and reproduction in any medium or format, as long as you give appropriate credit to the original author(s) and the source, provide a link to the Creative Commons licence, and indicate if changes were made. The images or other third party material in this article are included in the article's Creative Commons licence, unless indicated otherwise in a credit line to the material. If material is not included in the article's Creative Commons licence and your intended use is not permitted by statutory regulation or exceeds the permitted use, you will need to obtain permission directly from the copyright holder. To view a copy of this licence, visit http://creativecommons.org/licenses/by/4.0/.

\section{References}

1. Bridgwater A V. Thermochemical Processing of Biomass Conversion into Fuels, Chemicals and Power. New Jersey: Wiley, 2011,
157-199

2. Bridgwater A V. Review of fast pyrolysis of biomass and product upgrading. Biomass and Bioenergy, 2012, 38: 68-94

3. Demirbas A. Competitive liquid biofuels from biomass. Applied Energy, 2011, 88(1): 17-28

4. Kim T, Oh S, Kim J, Choi I, Choi J W. Study on the hydrodeoxygenative upgrading of crude bio-oil produced from woody biomass by fast pyrolysis. Energy, 2014, 68: 437-443

5. Xu Y, Long J, Liu Q, Li Y, Wang C, Zhang Q, Wei L, Zhang X, Qiu $\mathrm{S}$, Wang $\mathrm{T}$, et al. In situ hydrogenation of model compounds and raw bio-oil over Raney Ni catalyst. Energy Conversion and Management, 2015, 89: 188-196

6. Xiong W M, Fu Y, Zeng F X, Guo Q X. An in situ reduction approach for bio-oil hydroprocessing. Fuel Processing Technology, 2011, 92(8): 1599-1605

7. Gutiérrez Ortiz F J, Kruse A, Ramos F, Ollero P. Integral energy valorization of municipal solid waste reject fraction to biofuels. Energy Conversion and Management, 2019, 180: 1167-1184

8. Baiker A. Supercritical fluids in heterogeneous catalysis. Chemical Reviews, 1999, 99(2): 453-474

9. Guo Y, Wang S Z, Xu D H, Gong Y M, Ma H H, Tang X Y. Review of catalytic supercritical water gasification for hydrogen production from biomass. Renewable \& Sustainable Energy Reviews, 2010, 14 (1): 334-343

10. Prajitno H, Insyani R, Park J, Ryu C, Kim J. Non-catalytic upgrading of fast pyrolysis bio-oil in supercritical ethanol and combustion behavior of the upgraded oil. Applied Energy, 2016, 172: $12-22$

11. Ahmadi S, Yuan Z, Rohani S, Xu C. Effects of nano-structured CoMo catalysts on hydrodeoxygenation of fast pyrolysis oil in supercritical ethanol. Catalysis Today, 2016, 269: 182-194 
12. Tan K T, Lee K T. A review on supercritical fluids (SCF) technology in sustainable biodiesel production: Potential and challenges. Renewable \& Sustainable Energy Reviews, 2011, 15(5): 2452-2456

13. Peng J, Chen P, Lou H, Zheng X. Catalytic upgrading of bio-oil by HZSM-5 in sub- and super-critical ethanol. Bioresource Technology, 2009, 100(13): 3415-3418

14. Jo H, Prajitno H, Zeb H, Kim J. Upgrading low-boiling-fraction fast pyrolysis bio-oil using supercritical alcohol: Understanding alcohol participation, chemical composition, and energy efficiency. Energy Conversion and Management, 2017, 148: 197-209

15. Boucher M E, Chaala A, Pakdel H, Roy C. Bio-oils obtained by vacuum pyrolysis of softwood bark as a liquid fuel for gas turbines Part II: Stability and ageing of bio-oil and its blends with methanol and a pyrolytic aqueous phase. Biomass and Bioenergy, 2000, 19(5): 351-361

16. Nguyen D, Honnery D. Combustion of bio-oil ethanol blends at elevated pressure. Fuel, 2008, 87(2): 232-243

17. Oasmaa A, Kuoppala E, Selin J F, Gust S, Solantausta Y. Fast pyrolysis of forestry residue and pine 4 Improvement of the product quality by solvent addition. Energy \& Fuels, 2004, 18(5): 15781583

18. Pidtasang B, Sukkasi S, Pattiya A. Effect of in-situ addition of alcohol on yields and properties of bio-oil derived from fast pyrolysis of eucalyptus bark. Journal of Analytical and Applied Pyrolysis, 2016, 120: 82-93

19. Pidtasang B, Udomsap P, Sukkasi S, Chollacoop N, Pattiya A. Influence of alcohol addition on properties of bio-oil produced from fast pyrolysis of eucalyptus bark in a free-fall reactor. Journal of Industrial and Engineering Chemistry, 2013, 19(6): 1851-1857

20. Krutof A, Hawboldt K. Blends of pyrolysis oil, petroleum, and other bio-based fuels: A review. Renewable \& Sustainable Energy Reviews, 2016, 59: 406-419

21. Weerachanchai $P$, Tangsathitkulchai C, Tangsathitkulchai M. Phase behaviors and fuel properties of bio-oil-diesel-alcohol blends. World Academy of Science, Engineering and Technology, 2009, 32(8): 387-393

22. Yu F, Deng S, Chen P, Liu Y, Wan Y, Olson A, Kittelson D, Ruan R. Physical and chemical properties of bio-oils from microwave pyrolysis of corn stover. Applied Biochemistry and Biotechnology, 2007, 137-140(1-12): 957-970

23. Mante O D, Agblevor F A. Storage stability of biocrude oils from fast pyrolysis of poultry litter. Waste Management (New York, N. Y.), 2012, 32(1): 67-76

24. Udomsap P, Yeinn Y H, Hui J T H, Yoosuk B, Yusuf S B, Sukkasi S. Towards stabilization of bio-oil by addition of antioxidants and solvents, and emulsification with conventional hydrocarbon fuels. International Conference \& Utility Exhibition on Power and Energy Systems: Issues and Prospects for Asia (ICUE), 2011, 1-5

25. Diebold J P, Czernik S. Additives to lower and stabilize the viscosity of pyrolysis oils during storage. Energy \& Fuels, 1997, 11(10): 1081-1091

26. Zhang X, Tang W, Zhang Q, Li Y, Chen L, Xu Y, Wang C, Ma L. Production of hydrocarbon fuels from heavy fraction of bio-oil through hydrodeoxygenative upgrading with Ru-based catalyst. Fuel, 2018, 215: 825-834

27. Zhang J, Luo Z, Dang Q, Wang J, Chen W. Upgrading of bio-oil over bifunctional catalysts in supercritical monoalcohols. Energy \& Fuels, 2012, 26(5): 2990-2995

28. Shafaghat H, Kim J M, Lee I G, Jae J, Jung S C, Park Y K. Catalytic hydrodeoxygenation of crude bio-oil in supercritical methanol using supported nickel catalysts. Renewable Energy, 2019, 144: 159-166

29. Shakya R, Adhikari S, Mahadevan R, Hassan E B, Dempster T A. Catalytic upgrading of bio-oil produced from hydrothermal liquefaction of Nannochloropsis sp. Bioresource Technology, 2018, 252: 28-36

30. Zhang Z, Wang Q, Tripathi P, Pittman C U Jr. Catalytic upgrading of bio-oil using 1-octene and 1-butanol over sulfonic acid resin catalysts. Green Chemistry, 2011, 13(4): 940-949

31. Li W, Pan C, Sheng L, Liu Z, Chen P, Lou H, Zheng X. Upgrading of high-boiling fraction of bio-oil in supercritical methanol. Bioresource Technology, 2011, 102(19): 9223-9228

32. Cheng S, Wei L, Julson J, Rabnawaz M. Upgrading pyrolysis bio-oil through hydrodeoxygenation (HDO) using non-sulfided $\mathrm{Fe}-\mathrm{Co} / \mathrm{SiO}_{2}$ catalyst. Energy Conversion and Management, 2017, 150: 331-342

33. Duan P, Savage P E. Upgrading of crude algal bio-oil in supercritical water. Bioresource Technology, 2011, 102(2): 18991906

34. Boundy B, Diegel S, Wright L D S. Biomass Energy Data Book. $4^{\text {th }}$ ed. US Department of Energy, 2011, 201

35. Tang Z, Zhang Y, Guo Q. Catalytic hydrocracking of pyrolytic lignin to liquid fuel in supercritical ethanol. Industrial \& Engineering Chemistry Research, 2010, 49(5): 2040-2046

36. Zhang Q, Xu Y, Li Y, Wang T, Zhang Q, Ma L, He M, Li K. Investigation on the esterification by using supercritical ethanol for bio-oil upgrading. Applied Energy, 2015, 160: 633-640

37. Zhang X, Chen L, Kong W, Wang T, Zhang Q, Long J, Xu Y, Ma L. Upgrading of bio-oil to boiler fuel by catalytic hydrotreatment and esterification in an efficient process. Energy, 2015, 84: 83-90

38. Li W, Pan C, Zhang Q, Liu Z, Peng J, Chen P, Lou H, Zheng X. Upgrading of low-boiling fraction of bio-oil in supercritical methanol and reaction network. Bioresource Technology, 2011, 102(7): 4884-4889

39. Zhang C, Duan P, Xu Y, Wang B, Wang F, Zhang L. Catalytic upgrading of duckweed biocrude in subcritical water. Bioresource Technology, 2014, 166: 37-44

40. Ramón J, Arauzo J, Garcia L, Arcelus-Arrillaga P, Millan M, Suelves I, Pinilla J L. Bio-oil upgrading in supercritical water using Ni-Co catalysts supported on carbon nanofibres. Fuel Processing Technology, 2016, 154: 178-187

41. Zhang X, Zhang Q, Wang T, Li B, Xu Y, Ma L. Efficient upgrading process for production of low quality fuel from bio-oil. Fuel, 2016, 179: 312-321

42. Tang Z, Lu Q, Zhang Y, Zhu X, Guo Q. One step bio-oil upgrading through hydrotreatment, esterification, and cracking. Industrial \& Engineering Chemistry Research, 2009, 48(15): 6923-6929

43. Nishimura S, Ikeda N, Ebitani K. Selective hydrogenation of biomass-derived 5-hydroxymethylfurfural (HMF) to 2,5-dimethylfuran (DMF) under atmospheric hydrogen pressure over carbon supported PdAu bimetallic catalyst. Catalysis Today, 2014, 232: 8998

44. Wang X, Liu Y, Liang X. Hydrogenolysis of 5-hydroxymethylfurfural to 2,5-dimethylfuran over supported Pt-Co bimetallic catalysts 
under mild conditions. Green Chemistry, 2018, 20(12): 2894-2902

45. Román-Leshkov Y, Barrett C J, Liu Z Y, Dumesic J A. Production of dimethylfuran for liquid fuels from biomass-derived carbohydrates. Nature, 2007, 447(7147): 982-985

46. Capunitan J A, Capareda S C. Characterization and separation of corn stover bio-oil by fractional distillation. Fuel, 2013, 112: 6073

47. Duan P, Zhang C, Wang F, Fu J, Lü X, Xu Y, Shi X. Activated carbons for the hydrothermal upgrading of crude duckweed bio-oil. Catalysis Today, 2016, 274: 73-81

48. Meng J, Moore A, Tilotta D C, Kelley S S, Adhikari S, Park S. Thermal and storage stability of bio-oil from pyrolysis of torrefied wood. Energy \& Fuels, 2015, 29(8): 5117-5126

49. He Z, Xu D, Wang S, Zhang H, Jing Z. Catalytic upgrading of watersoluble biocrude from hydrothermal liquefaction of chlorella. Energy \& Fuels, 2018, 32(2): 1893-1899 